\title{
Aplicação da geotecnologia no estudo de cadastro técnico rural e no mapeamento de áreas de preservação permanente e reservas legais
}

\author{
Joel Gripp Junior ${ }^{1}$, Vicente Paulo Soares ${ }^{2}$, Carlos Antonio Álvares Soares Ribeiro ${ }^{3}$, Agostinho Lopes de Souza ${ }^{2}$, \\ José Marinaldo Gleriani ${ }^{4}$
}

\section{RESUMO}

Este trabalho teve como objetivo principal mapear as classes de cobertura e o uso da terra, bem como as áreas de preservação permanente (APPs) e de reservas legais de imóveis rurais. A área de estudo compreendeu parte dos municípios de Canaã, Araponga e Ervália, Estado de Minas Gerais. Foi utilizada uma imagem ortorretificada de alta resolução do sensor Ikonos II com 1 m de resolução espacial. A partir da interpretação visual da imagem, foram criadas sete classes temáticas, a saber: cobertura florestal, pasto sujo, pasto limpo, cafezal, edificações, área agrícola e reflorestamento. As APPs foram obtidas a partir de um modelo digital de elevação hidrologicamente consistente. Os resultados mostraram a predominância das classes de cafezal com 24,5\% e de cobertura florestal com 28,8\%, perfazendo mais de 50\% da área de estudo. As áreas delimitadas como de preservação permanente totalizaram 55,1\%.

Palavras-chave: Imóveis rurais, mapeamento, sistemas de informações geográficas.

\section{ABSTRACT \\ Use of geoprocessing techniques for mapping permanent preservation areas (PPAs) and legal reserve areas (LRA) in farms}

The main objective of this work was to map land use/land cover classes, permanent preservation areas and legal reserve areas in farms. The study area comprised part of the municipalities of Canaã, Araponga and Ervália, in the State of Minas Gerais, Brazil. A high resolution ortorectified image from the sensor Ikonos II with a 1-m spatial resolution was used for the study. The visual image interpretation generated 7 thematic map classes: forest cover, “clean” pasture and “overgrown” pasture, coffee plantation, build areas and areas of farming and reforestation. The permanent preservation areas were obtained from a hydrologically consistent digital elevation model. Results showed a predominance of the classes coffee plantation (24.5\%) and forest cover (28.8\%), totalizing more the $50 \%$ of the study area. Permanent preservation areas occupied $55.1 \%$.

Key words: Farms, geographical information systems, mapping.

\footnotetext{
Recebido para publicação em abril de 2009 e aprovado em junho de 2010

${ }^{1}$ Engenheiro Agrimensor, Doutor. Departamento de Engenharia Civil, Universidade Federal de Viçosa, Av. Peter Henry Rolfs, s/n, 36570-000 Viçosa, MG, Brasil. jgripp@ufv.br 2 Engenheiro Florestal, Doutor. Departamento de Engenharia Florestal, Universidade Federal de Viçosa, Av. Peter Henry Rolfs, s/n, 36570-000 Viçosa, MG, Brasil. vicente@ufv.br, souza@ufv.br

${ }^{3}$ Engenheiro Agrícola, Doutor. Departamento de Engenharia Florestal, Universidade Federal de Viçosa, Av. Peter Henry Rolfs, s/n, 36570-000 Viçosa, MG, Brasil. cribeiro@ufv.br ${ }^{4}$ Engenheiro Agrônomo, Doutor. Departamento de Engenharia Florestal, Av. Peter Henry Rolfs, s/n, 36570-000 Viçosa, MG, Brasil. gleriani@ufv.br
} 


\section{INTRODUÇÃO}

Com a publicação da Lei Federal número 10.267, de 28 de agosto de 2001, ficou instituído o CNIR - Cadastro Nacional de Imóveis Rurais, o que torna obrigatório o georreferenciamento de imóveis rurais. Isto é, as coordenadas que definem os limites dos imóveis e as posições das reservas legais devem estar referenciadas no Sistema Geodésico Brasileiro.

Uma das finalidades da criação dessa legislação foi buscar soluções para problemas relacionados a limites de propriedades rurais e padronizar a informação no registro imobiliário e no cadastro de imóveis rurais. Como consequência da implantação da legislação, tem-se a possibilidade de realizar um mapeamento georreferenciado dos imóveis rurais, que são unidades territoriais de fundamental importância para o monitoramento ambiental por meio de um sistema de informações geográficas (SIG). Além do mapa da propriedade, no SIG pode-se inserir outras informações, cadastrais ou não, e realizar diversos estudos no imóvel, como conflito de uso do solo, dentre outros.

Na realização do georreferenciamento, o sistema de posicionamento global (GPS) é uma ferramenta indispensável para delimitar a propriedade rural numa forma que pode ser tida como "perfeitamente conhecida" (Segantine, 2005). Outras vantagens importantes para o cadastro podem ser alcançadas integrando-se o conhecimento dos limites dos imóveis com a riqueza de informações que as imagens de satélites de alta resolução proporcionam.

Silva \& Lock (1996) ressaltam que um cadastro técnico multifinalitário rural corresponde a um conjunto de mapas temáticos e informações descritivas sobre uma base cartográfica. Os dados cadastrais, que podem ser descritivos ou posicionais, como nome do imóvel, do proprietário, do local, área etc., devem ser confiáveis a todo momento, caracterizando, portanto, a manutenção como atividade vital durante a implantação do sistema cadastral.

Para a preservação do meio ambiente, em atendimento à legislação ambiental, diversas providências têm sido tomadas, entre elas pode-se dizer a exigência de reservas legais nas propriedades rurais, bem como a não-utilização das áreas de preservação permanente. Nesse contexto, deve-se conservar os fragmentos florestais que ainda restam na propriedade, para consolidar a conservação e o uso econômico de seus bens e serviços. Para isso, faz-se necessário prover estudos que busquem conhecer esse ambiente em detalhes, por meio das tecnologias e técnicas existentes (Gandolfi et al. 1995).

As áreas de preservação permanentes (APPs) foram definidas em lei para evitar a degradação do ecossistema, conservar o meio ambiente e manter a qualidade de vida. No código florestal brasileiro (Lei número 4.771/1965) as APPs são caracterizadas da seguinte forma: de acordo com os artigos $2^{\circ}$ e $3^{\circ}$ dessa Lei, “considera-se área de preserva- ção permanente aquela protegida, coberta ou não, por vegetação nativa, com a função ambiental de preservar os recursos hídricos, a paisagem, a estabilidade geológica, a biodiversidade, e o fluxo gênico de fauna e flora, proteger o solo e assegurar o bem-estar das populações humanas, não se permitindo ali exploração direta (madeira, agricultura ou pecuária), mesmo que com manejo” (Brasil, 1965).

Diversos trabalhos sobre o mapeamento de áreas de preservação permanente têm sido realizados nos últimos anos, podendo-se citar os de Nascimento et al. (2005), Ribeiro et al. (2005), Soares et al. (2007) e Oliveira et al. (2008), dentre outros.

O código florestal, em seu artigo $1^{\circ}$, parágrafo $2^{\circ}$, inciso III, define a reserva legal como: "área localizada no interior de uma propriedade ou posse rural, excetuada a de preservação permanente, necessária ao uso sustentável dos recursos naturais, à conservação e reabilitação dos processos ecológicos, à conservação da biodiversidade e ao abrigo e proteção da fauna e flora nativas” (Brasil, 1965).

A área de reserva legal (ARL) é obrigatória em todo o imóvel rural. Nela não é permitido o corte raso da vegetação. O artigo 16 do Código Florestal Brasileiro (Lei número 4.771/1965) estabelece os percentuais mínimos em função da localização. Imóveis situados em área de floresta localizada na Amazônia Legal tem o percentual de $80 \%$, e nas propriedades situadas em área de floresta ou outras formas de vegetação nativa localizada nas demais regiões do País o percentual é 20\% (Brasil, 1965).

Em 2002, entrou em vigor no Estado de Minas Gerais a Lei número 14.309, que dispõe sobre as políticas florestais e de proteção à biodiversidade no Estado. Essa lei apresenta algumas importantes particularidades com relação à legislação federal (Minas Gerais, 2002).

O artigo 16 da lei estadual define como a reserva legal deve ser demarcada, ou seja, a demarcação da reserva legal é a critério da autoridade competente, e deve ser, preferencialmente, em terreno contínuo e com cobertura vegetal nativa. No seu $\S 1^{\circ} \mathrm{diz}$ : Respeitadas as peculiaridades locais e o uso econômico da propriedade, a reserva legal será demarcada em continuidade a outras áreas protegidas, evitando-se a fragmentação dos remanescentes da vegetação nativa e mantendo-se os corredores necessários ao abrigo e ao deslocamento da fauna silvestre.

O presente trabalho teve como objetivo principal o mapeamento da cobertura para a caracterização do uso da terra para reservas legais, áreas de preservação permanente e outras informações pertinentes a um cadastro técnico rural.

\section{MATERIAL E MÉTODOS}

\section{Área de estudo}

A área de estudo está situada na Zona da Mata do Estado de Minas Gerais, e compreende um trecho da 
bacia hidrográfica de contribuição da Usina Hidrelétrica Casquinha, pertencente à Universidade Federal de Viçosa. É composta por partes dos municípios de Canaã, Araponga e Ervália. A área localiza-se entre os meridianos de $42^{\circ} 31^{\prime} 19^{\prime \prime} \mathrm{W}$ e $42^{\circ} 37^{\prime} 2^{\prime \prime}$ "W e entre os paralelos $20^{\circ} 40^{\prime} 22^{\prime \prime}$ S e $20^{\circ} 45^{\prime} 41^{\prime \prime}$ S (Figura 1). A escolha dessa área foi devido à existência de imagens recentes e de alta resolução espacial (imagens do IKONOS II). Teve também como motivação o fato de a região ser representativa da fisiologia da Zona da Mata mineira, ou seja, caracterizada por um relevo que varia de ondulado a montanhoso, com altitude mínima de 647 e máxima de $1.288 \mathrm{~m}$.

A vegetação natural da região é classificada como Floresta Estacional Semidecidual, ou seja, parte das espécies arbóreas perde folhas no período correspondente ao inverno. Esse tipo de vegetação é condicionado pelo comportamento estacional do clima, que apresenta verão quente com chuvas intensas, e inverno seco com queda acentuada de temperatura, (Meira, 2006).

Parte considerável da região das terras na área de estudo é utilizada para a agricultura, principalmente para as culturas de milho, café e feijão, sendo também utilizada para a pecuária, com grandes porções de terras em pastagens limpas e sujas.

\section{Materiais e softwares utilizados}

Os materiais utilizados no desenvolvimento deste trabalho incluíram uma imagem Ikonos II ortorretificada, com $1 \mathrm{~m}$ de resolução espacial, obtida em maio de 2005; cartas do IBGE no formato digital, folhas SF-23-X-B-V-2 - São Miguel do Anta, e SF-23-X-B-V-4 - Ervália; quatro receptores de uma frequência GPS, Promark 2; um receptor de duas frequências, Novatel e os aplicativos ArcGIS 9.2, OrthoEngine e Focus (PCI Geomatics), Ashtech Solution 2.6 e TGOffice $v 1.63$.

A imagem IKONOS II com alta resolução espacial permite chegar a uma boa precisão em tarefas de identificação de cobertura e uso da terra. Como exemplo, pode-se ver um trecho da área de estudo na Figura 2, em que é possível visualizar lavouras de café, mata nativa, capoeira, edificações, pasto sujo etc.

\section{Atividades desenvolvidas}

\section{Ortorretificação da imagem IKONOS II}

Uma vez que a imagem IKONOS II tipo GEO apresenta simplesmente correção geométrica com georreferenciamento e o relevo da região é fortemente ondulado e montanhoso, decidiu-se ortorretificar a imagem para eliminar as deformações geométricas causadas pelo relevo. Para proceder a ortorretificação, além de ser necessário o MDT do terreno e pontos de controles, é necessário também a utilização de algum aplicativo ou programa de computa- dor que efetue a operação. Para ortorretificar a imagem empregou-se o programa OrthoEngine do PCI Geomatics, pertencente ao Instituto de Geociências Aplicadas de Minas Gerais IGA-MG. O MDT da região em estudo foi obtido usando o mapeamento digital do IBGE, originário da escala $1 / 50.000$ e com equidistância de 20 m, já os pontos de controle foram obtidos a partir do GPS com no mínimo uma hora de rastreio.

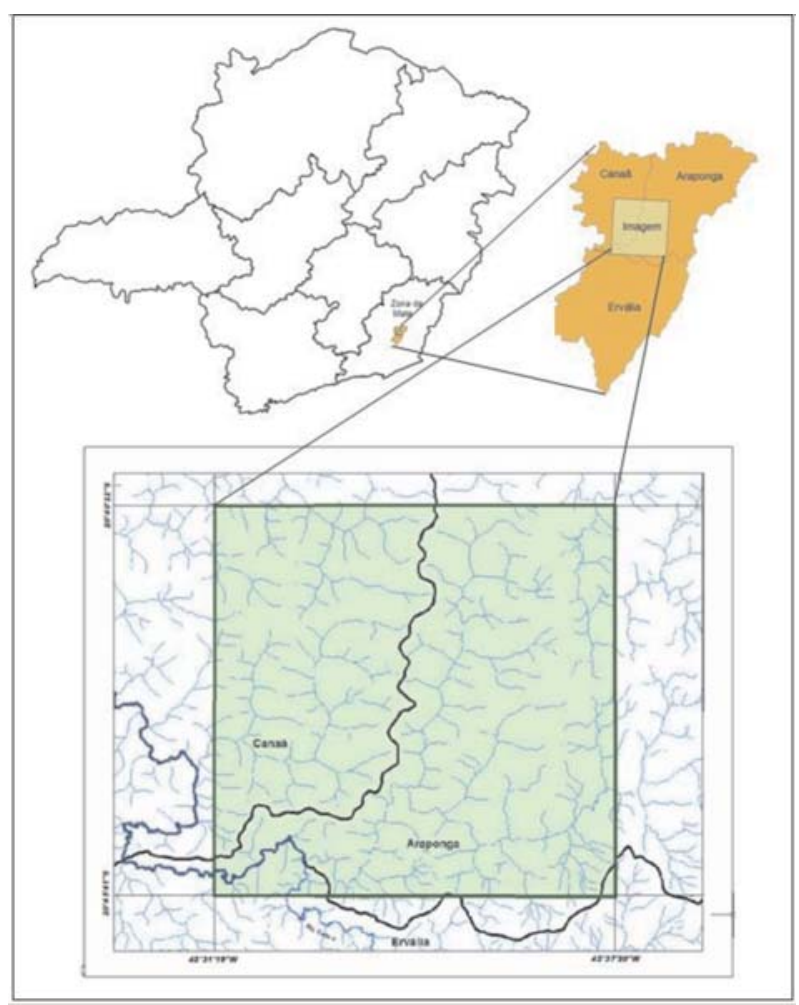

Figura 1. Área de estudo mostrando parte dos municípios abrangidos pela imagem IKONOS II.

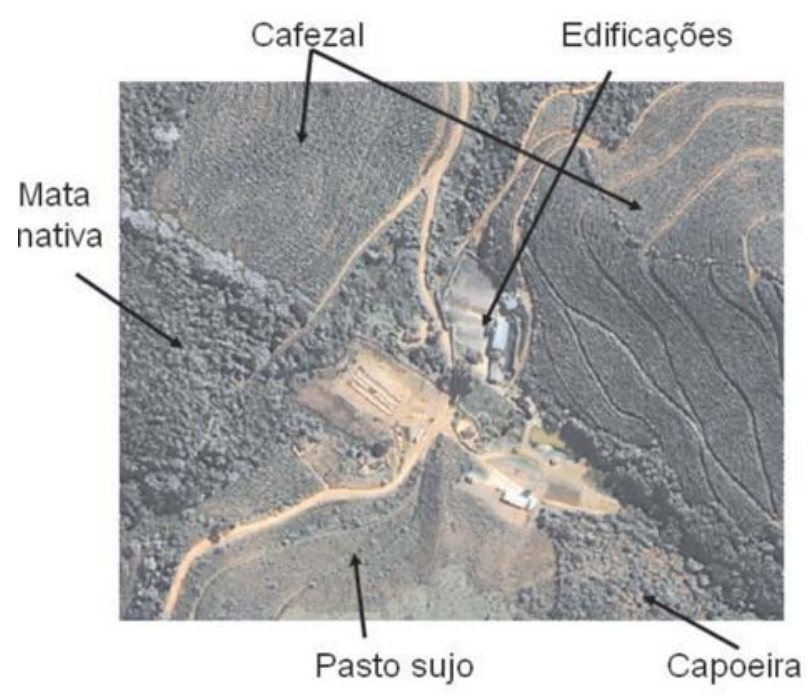

Figura 2. Trecho da Imagem do sensor IKONOS II usada neste estudo, mostrando a identificação dos diferentes usos da terra. 


\section{Delimitação das unidades imobiliárias existentes na área de estudo}

Para o presente trabalho foram delimitadas sobre a imagem IKONOS II (ortoimagem) as linhas divisórias de 30 propriedades rurais, com base em entrevistas com proprietários no campo. A área total do trecho de estudo foi de aproximadamente 1.214 ha.

\section{Mapeamento das classes de cobertura e uso da terra}

Após a delimitação dos imóveis na ortoimagem com o devido posicionamento de suas linhas divisórias, passou-se às atividades de interpretação visual das classes de cobertura e uso da terra, em que foram constatadas as seguintes classes temáticas: cafezal, área agrícola, reflorestamento, pasto limpo, pasto sujo, cobertura florestal e edificações (Tabela 1).

\section{Delimitação e quantificação das áreas de preservação permanente e reservas legais}

A delimitação das áreas de preservação permanente (APPs), de acordo com a Resolução n ${ }^{\circ} 303$ do CONAMA, foi realizada por meio do método desenvolvido por Ribeiro et al. (2005), implementada para aplicar a partir do modelo digital de elevação hidrologicamente consistente (MDEHC) e usando ferramentas presentes ou desenvolvidas para serem utilizadas no programa ARCGIS.

Inicialmente, foram delimitadas as diversas modalidades de APPs, ou seja, de topos de morros, margens de cursos de água, de declividade, linhas de cumeada e de nascentes e suas áreas de contribuição. Como neste trabalho o interesse foi simplesmente definir as APPs, não importando a modalidade, foi feito um mapa contendo a união de todas as APPs.

Tabela 1. Definição das classes de cobertura e uso da terra mapeada na imagem

\begin{tabular}{|c|c|c|}
\hline Classe temática & Chave de interpretação & Descrição \\
\hline Cobertura florestal & ats & $\begin{array}{l}\text { Áreas cobertas com vegetação nativa nos diferentes estágios de } \\
\text { vegetação (capoeira, mata) }\end{array}$ \\
\hline Pasto sujo & & Pequenos arbustos associados à pastagem abandonada \\
\hline Pasto limpo & & Áreas transformadas para o pastoreio \\
\hline Cafezal & & Cultura perene \\
\hline Áreaagrícola & & Culturas anuais (milho, feijão, hortaliças etc.) \\
\hline Reflorestamento & & Áreas com plantio de eucalipto e pínus \\
\hline Edificações & & $\begin{array}{l}\text { Edificações e benfeitorias (Casas de colonos, terreiros de } \\
\text { secagens de grãos, tulhas etc.) }\end{array}$ \\
\hline
\end{tabular}

Rev. Ceres, Viçosa, v. 57, n.4, p. 459-468, jul/ago, 2010 


\section{RESULTADOS E DISCUSSÃO}

\section{Mapeamento dos imóveis com as classes de cobertura e uso da terra}

A Figura 3 mostra o mapa da área de estudo contendo as classes temáticas de cobertura e uso da terra e as linhas divisórias dos 30 imóveis delimitados. Análise qualitativa dessa figura mostra predominância de cafezal, pastagens e cobertura florestal, o que pode ser comprovado quantitativamente pelos dados constantes da Tabela 2. De acordo com os resultados contidos nessa tabela, aproximadamente $65 \%$ do uso da terra na área de estudo é com cafezal, pastagens, áreas agrícolas e reflorestamento, o que caracteriza intenso uso antrópico.

A sobreposição dos limites dos imóveis sobre o mapa temático obtido da interpretação da imagem IKONOS II permitiu obter o uso e a ocupação da terra por propriedade, conforme pode ser visto na Tabela 3. As informações constantes nessa tabela foram obtidas com o uso das ferramentas do módulo Arcmap do programa ARCGIS 9.2.
Tabela 2. Áreas das classes de cobertura e uso da terra

\begin{tabular}{lcc}
\hline Uso e cobertura da terra & Área (ha) & \% \\
\hline Cafezal & 298,60 & $24,59 \%$ \\
Área agrícola & 31,39 & $2,59 \%$ \\
Pasto limpo & 367,18 & $30,24 \%$ \\
Pasto sujo & 134,40 & $11,07 \%$ \\
Reflorestamento & 23,43 & $1,93 \%$ \\
Edificações & 8,99 & $0,74 \%$ \\
Cobertura florestal & 350,03 & $28,83 \%$ \\
Total & $1.214,02$ & $100 \%$ \\
\hline
\end{tabular}

\section{Delimitação e quantificação das áreas de preservação permanentes e reservas legais}

Seguindo a Resolução n ${ }^{\circ} 303$ do CONAMA, foram delimitadas as modalidades de topos de morros, margens de cursos de água, declividade, e linhas de cumeada e de nascentes com suas bacias hidrográficas contribuintes, as quais se encontram na Figura 4. Pela análise visual da Figura 4, percebe-se que mais de $50 \%$ das terras estão situadas em APPs.

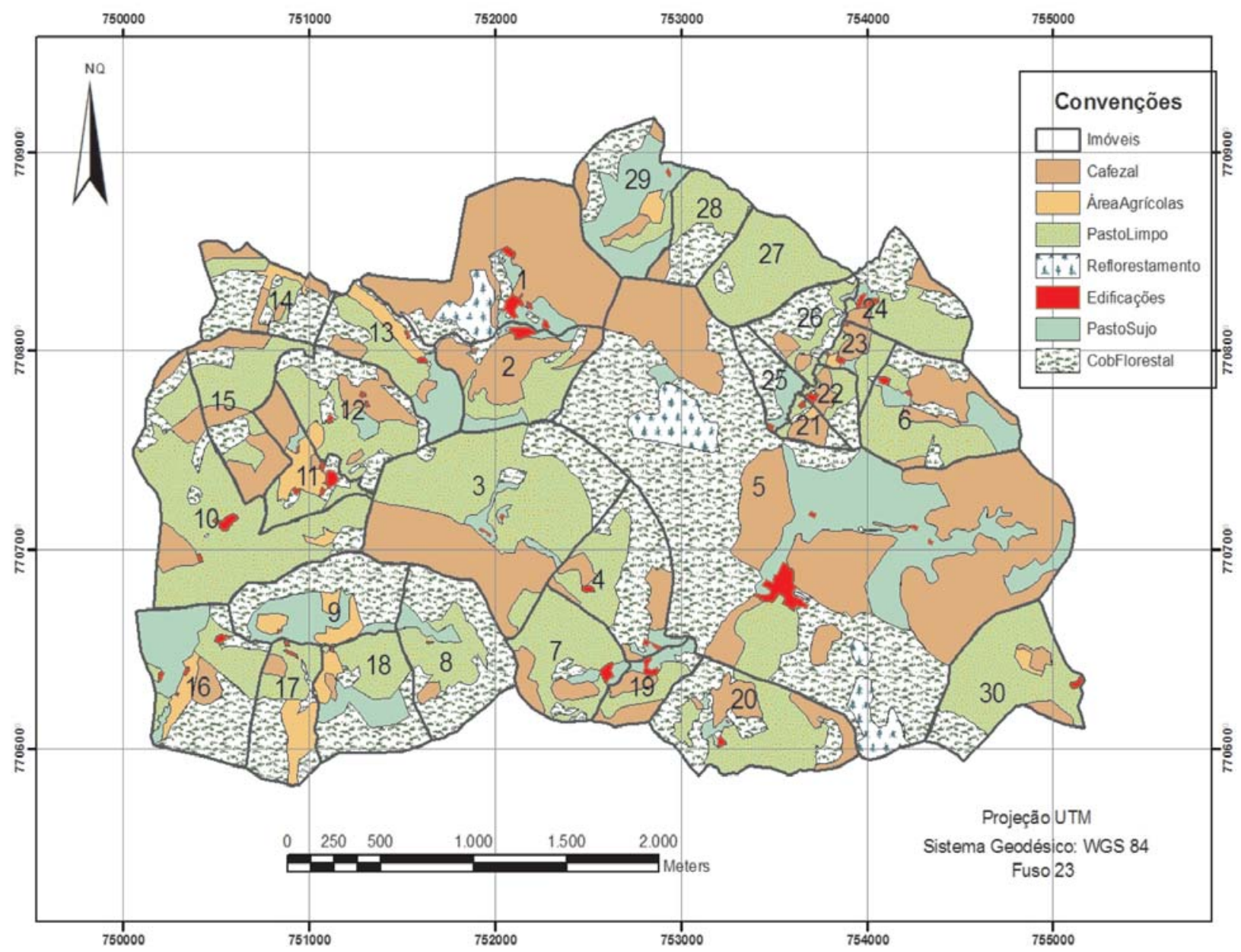

Figura 3. Mapa temático da área de estudo obtido por meio da interpretação visual da imagem IKONOS II e com linhas divisórias dos imóveis rurais. 
Tabela 3. Áreas dos imóveis e das classes de cobertura e uso da terra

\begin{tabular}{|c|c|c|c|c|c|c|c|c|}
\hline \multirow[b]{2}{*}{ Imóvel } & \multicolumn{8}{|c|}{ Área (ha) } \\
\hline & Área & Cafezal & $\begin{array}{c}\text { Cobertura } \\
\text { florestal }\end{array}$ & $\begin{array}{c}\text { Área } \\
\text { agrícola }\end{array}$ & $\begin{array}{l}\text { Pasto } \\
\text { limpo }\end{array}$ & $\begin{array}{l}\text { Pasto } \\
\text { sujo }\end{array}$ & Reflorestamento & Edificações \\
\hline 1 & 65,85 & 49,21 & 4,62 & & & 4,52 & 6,1114 & 1,32 \\
\hline 2 & 32,29 & 15,32 & 2,57 & & 10,05 & 3,58 & & 0,75 \\
\hline 3 & 91,09 & 28,83 & 13,21 & & 45,79 & 3,08 & & 0,19 \\
\hline 4 & 34,95 & 6,36 & 15,35 & & 11,11 & 1,72 & & 0,42 \\
\hline 5 & 313,27 & 111,84 & 121,81 & & 10,15 & 49,05 & 17,3258 & 0,31 \\
\hline 6 & 37,39 & 9,35 & 5,98 & & 15,74 & 5,97 & & 0,30 \\
\hline 7 & 43,10 & 8,91 & 13,61 & & 19,09 & 1,24 & & 0,21 \\
\hline 8 & 37,28 & 0,91 & 22,68 & & 11,23 & 2,48 & & 0,06 \\
\hline 9 & 33,07 & & 18,68 & 4,77 & & 9,63 & & 0,04 \\
\hline 10 & 68,17 & 6,71 & 7,23 & 0,81 & 52,92 & & & 0,67 \\
\hline 11 & 17,92 & 4,58 & 1,59 & 4,66 & 5,57 & 0,658 & & 0,88 \\
\hline 12 & 35,02 & 6,40 & 10,94 & 0,95 & 15,29 & 1,274 & & 0,30 \\
\hline 13 & 26,57 & 2,36 & 4,58 & 1,51 & 8,81 & 7,177 & & 0,22 \\
\hline 14 & 24,67 & 4,49 & 14,02 & & 4,59 & & & \\
\hline 15 & 30,26 & 10,90 & 4,50 & 2,87 & 14,95 & & & \\
\hline 16 & 41,99 & 2,58 & 15,65 & 5,26 & 8,54 & 11,80 & & 0,47 \\
\hline 17 & 23,07 & 1,09 & 9,73 & 5,26 & 6,69 & & & 0,20 \\
\hline 18 & 30,32 & 0,52 & 12,15 & 2,09 & 9,49 & 6,015 & & 0,05 \\
\hline 19 & 28,48 & 4,89 & 1,96 & & 19,48 & 1,666 & & 0,51 \\
\hline 20 & 12,63 & 4,50 & 0,81 & & 4,65 & 2,105 & & 0,50 \\
\hline 21 & 5,27 & 2,47 & 1,15 & 0,39 & 1,15 & & & 0,12 \\
\hline 22 & 7,93 & 1,84 & 2,74 & & 3,09 & & & 0,26 \\
\hline 23 & 8,27 & 2,32 & 0,09 & 0,33 & 4,80 & 0,42 & & 0,22 \\
\hline 24 & 25,41 & 2,81 & 8,70 & & 12,72 & 0,69 & & 0,51 \\
\hline 25 & 9,50 & & 6,47 & & & 2,77 & & 0,13 \\
\hline 26 & 15,66 & 1,70 & 9,15 & & 4,392 & 0,48 & & \\
\hline 27 & 26,59 & & 1,14 & & 25,55 & & & \\
\hline 28 & 18,48 & 1,31 & 7,05 & & 10,15 & & & \\
\hline 29 & 32,63 & 3,57 & 7,13 & 1,52 & 2,88 & 17,52 & & 0,08 \\
\hline 30 & 36,89 & 2,72 & 4,76 & 0,91 & 28,27 & & & 0,26 \\
\hline
\end{tabular}

Na Figura 5 está contido um mapa com as APPs e as classes de cobertura e uso da terra para os 30 imóveis analisados.

Ao comparar o mapa das Figuras 4 e 5, notam-se as APPs antropizadas pela prática de agricultura, pastagem e reflorestamento. Na Tabela 4 estão contidas informações quantitativas da área de cada imóvel rural, a área total das APPs dentro do imóvel, a porcentagem da área do imóvel ocupada em APP e a área de cada uso da terra dentro das APPs. Já na Tabela 5 são mostradas as áreas, em porcentagens, ocupadas pelas classes de cobertura e uso da terra em Áreas de Preservação Permanente.

Nota-se, pela Tabela 5, que 55,1\% das classes encontram-se em APPs, caracterizando uso indevido de acordo com a legislação vigente. Em um estudo conduzido na microbacia do paraíso, município de Viçosa, Minas Gerais, em condições de relevo similares à do presente estudo, Soares et al. (2002) encontraram que 65\% da área da microbacia é de preservação permanente.
As reservas legais, que são as áreas de cobertura arbórea localizadas dentro dos imóveis, deveriam estar bem definidas e até averbadas na escritura da matrícula dos imóveis (Lei n ${ }^{\circ} 4.771 / 65$, art. 16), porém, na prática, observou-se que isso não tem ocorrido, o que coloca o imóvel passível de multa, com base no Decreto Federal número 6.514, de 22 de julho de 2008. Neste trabalho foram consideradas como reservas legais as áreas cobertas com vegetação nativa e de diferentes fisionomias nos diversos estádios de vegetação (coberturas florestais).

Na Figura 6 encontra-se o mapeamento das coberturas florestais existentes nos imóveis, onde pode ser verificado se eles estão situados ou não nas APPs. A Tabela 6 mostra os 30 imóveis com suas áreas totais, áreas em APPs, áreas totais em coberturas florestais, porcentagem da área do imóvel em cobertura florestal, área de cobertura florestal fora de APPs e porcentagem da cobertura florestal fora de APPs. 


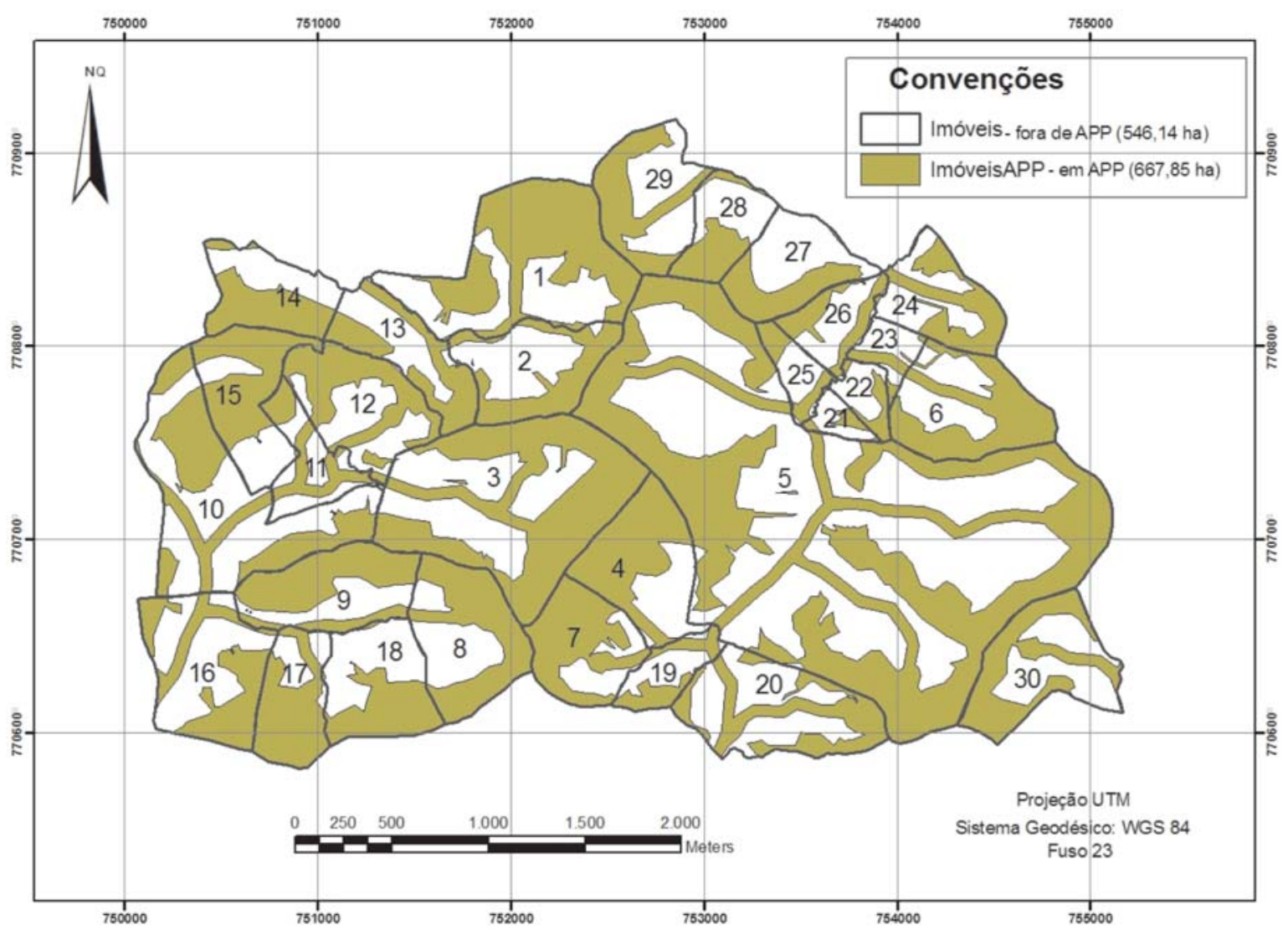

Figura 4. Imóveis rurais e suas áreas de preservação permanente delimitadas na área de estudo



Figura 5 . Mapeamento das classes de cobertura e uso das terras situadas em áreas de preservação permanente. 
Tabela 4 - Imóveis com suas áreas totais e áreas utilizadas em APPs (ha)

\begin{tabular}{|c|c|c|c|c|c|c|c|c|c|c|c|}
\hline Imóvel & Área & APP total & $\begin{array}{c}\text { \% do imóvel } \\
\text { em APP }\end{array}$ & Cafezal & $\begin{array}{c}\text { Café em } \\
\text { APP }\end{array}$ & $\begin{array}{c}\text { Áreas } \\
\text { agrícolas }\end{array}$ & $\begin{array}{c}\text { AAgr em } \\
\text { APP }\end{array}$ & $\begin{array}{l}\text { Pasto } \\
\text { limpo }\end{array}$ & $\begin{array}{c}\text { Pasto L em } \\
\text { APP }\end{array}$ & Pasto sujo & $\begin{array}{c}\text { Pasto } \mathrm{S} \text { em } \\
\text { APP }\end{array}$ \\
\hline 1 & 65,84 & 42,24 & 64,2 & 49,21 & 35,63 & & & & & 4,52 & 1,41 \\
\hline 2 & 32,28 & 15,99 & 49,5 & 15,31 & 3,56 & & & 10,05 & 7,29 & 3,58 & 3,29 \\
\hline 3 & 91,08 & 57,66 & 63,3 & 28,83 & 16,52 & & & 45,79 & 26,19 & 3,08 & 2,29 \\
\hline 4 & 34,95 & 23,73 & 67,9 & 6,36 & 2,75 & & & 11,11 & 10,76 & 1,72 & 0,38 \\
\hline 5 & 313,26 & 155,41 & 49,6 & 111,84 & 47,10 & & & 10,15 & 4,47 & 49,05 & 22,41 \\
\hline 6 & 37,38 & 23,90 & 64,0 & 9,35 & 4,72 & & & 15,74 & 9,80 & 5,97 & 5,19 \\
\hline 7 & 43,09 & 20,13 & 46,7 & 8,90 & 3,94 & & & 19,09 & 7,24 & 1,23 & 0,99 \\
\hline 8 & 37,27 & 23,32 & 62,6 & 0,91 & 0,02 & & & 11,23 & 3,03 & 2,48 & 1,27 \\
\hline 9 & 33,07 & 23,15 & 70,0 & & 0 & 4,77 & 2,20 & & & 9,63 & 5,77 \\
\hline 10 & 68,17 & 32,76 & 48,1 & 6,70 & 4,06 & 0,81 & 0,35 & 52,9 & 22,81 & & \\
\hline 11 & 17,92 & 8,84 & 49,3 & 4,58 & 2,84 & 4,66 & 1,95 & 5,57 & 1,74 & 0,65 & 0,60 \\
\hline 12 & 35,01 & 19,61 & 56,0 & 6,40 & 3,11 & 0,95 & 0,29 & 15,29 & 6,61 & 1,27 & 0,56 \\
\hline 13 & 26,56 & 15,72 & 59,2 & 2,35 & 1,93 & 3,42 & 1,77 & 8,81 & 2,04 & 7,17 & 6,27 \\
\hline 14 & 24,66 & 14,50 & 58,8 & 4,48 & 2,56 & 1,513 & & 4,58 & 1,35 & & \\
\hline 15 & 30,25 & 19,93 & 65,9 & 10,89 & 5,19 & & & 14,95 & 10,56 & & \\
\hline 16 & 41,99 & 20,28 & 48,3 & 2,57 & 0,18 & 2,87 & 0,02 & 8,54 & 4,12 & 11,79 & 6,09 \\
\hline 17 & 23,06 & 17,73 & 76,9 & 1,09 & 0,15 & 5,26 & 4,83 & 6,68 & 2,95 & & \\
\hline 18 & 30,31 & 14,42 & 47,6 & 0,51 & 0 & 2,09 & 0,02 & 9,48 & 0,90 & 6,01 & 3,96 \\
\hline 19 & 28,47 & 21,39 & 75,1 & 4,88 & 3,02 & & & 19,47 & 15,06 & 1,66 & 1,29 \\
\hline 20 & 12,63 & 6,36 & 50,4 & 4,50 & 2,63 & & & 4,65 & 1,46 & 2,10 & 1,44 \\
\hline 21 & 5,27 & 1,62 & 30,9 & 2,46 & 0,85 & 0,39 & 0,04 & 1,149 & 0,38 & & \\
\hline 22 & 7,92 & 2,89 & 36,5 & 1,83 & 0,05 & & & 3,08 & 0,96 & & \\
\hline 23 & 8,27 & 2,75 & 33,3 & 2,31 & 0,10 & 0,43 & 0,37 & 4,79 & 1,74 & 0,42 & 0,31 \\
\hline 24 & 25,41 & 14,02 & 55,2 & 2,80 & 0,93 & & & 12,72 & 7,43 & 0,68 & 0,10 \\
\hline 25 & 9,49 & 4,28 & 45,1 & & 0 & & & & & 2,77 & 1,37 \\
\hline 26 & 15,66 & 7,45 & 47,6 & 1,70 & 0,33 & & & 4,39 & 1,60 & 0,48 & 0,30 \\
\hline 27 & 26,59 & 11,57 & 43,5 & & 0 & & & 25,55 & 10,71 & & \\
\hline 28 & 18,47 & 8,91 & 48,3 & 1,31 & 1,27 & & & 10,14 & 1,48 & & \\
\hline 29 & 32,63 & 16,71 & 51,2 & 3,56 & 2,10 & 1,52 & 0,81 & 2,88 & 0,09 & 17,52 & 7,70 \\
\hline 30 & 36,88 & 20,45 & 55,5 & 2,72 & 0,28 & 0,91 & 0,43 & 28,27 & 14,78 & & \\
\hline
\end{tabular}

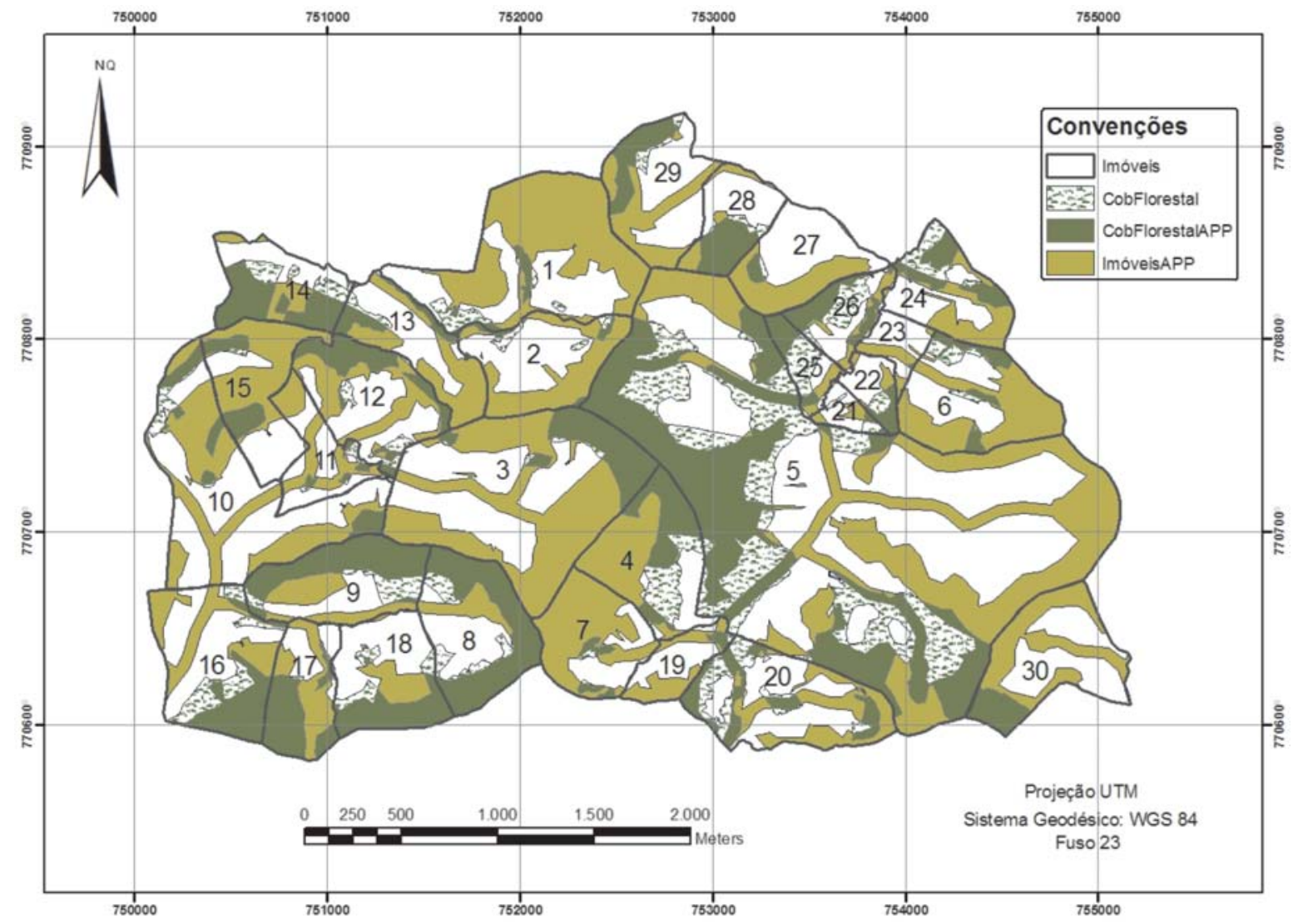

Figura 6. Mapeamento das áreas de cobertura florestal na área em estudo.

Rev. Ceres, Viçosa, v. 57, n.4, p. 459-468, jul/ago, 2010 
Pelas informações contidas na Tabela 6, verifica-se que entre os 30 imóveis em estudo 17 possuem áreas com cobertura florestal, perfazendo mais que $20 \%$ do imóvel no interior ou não de APPs. Já se for considerada a cobertura florestal fora de APP como reserva legal, apenas dois têm mais que 20\% de área com cobertura florestal. Para os demais imóveis, cuja cobertura flores- tal não atende ao mínimo de $20 \%$, deve-se selecionar outra classe de cobertura vegetal para ser recomposta no futuro.

\section{Cadastro técnico rural}

Feita uma consulta à superintendência do INCRA do Estado de Minas Gerais em meados de 2008, constatou-se

Tabela 5. Porcentagem das áreas ocupadas pelas classes de cobertura e uso da terra nas APPs

\begin{tabular}{lccc}
\hline & \multicolumn{2}{c}{ Área (ha) } & \multirow{2}{*}{ \% da área em APP } \\
\cline { 2 - 3 } & total & em APP & 55,1 \\
\hline Região & 1214,01 & 668,61 & 48,9 \\
Cafezal & 299,06 & 145,95 & 41,8 \\
Área agrícola & 31,40 & 13,13 & 48,4 \\
Pasto limpo & 367,18 & 177,89 & 54,6 \\
Pasto sujo & 133,89 & 73,10 & 40,0 \\
Euc. pínus & 23,44 & 9,36 & 51,4 \\
Edificações & 8,99 & 4,62 & 69,9 \\
Cobertura florestal & 350,04 & 244,55 & \\
\hline
\end{tabular}

Tabela 6. Área de cobertura florestal na área de estudo (ha)

\begin{tabular}{|c|c|c|c|c|c|c|c|}
\hline Imóvel & Área & APP total & $\begin{array}{l}\text { Cobertura } \\
\text { florestal }\end{array}$ & $\begin{array}{c}\text { \% do imóvel } \\
\text { em cob. } \\
\text { florestal }\end{array}$ & $\begin{array}{c}\text { Cobertura } \\
\text { florestal } \\
\text { em APP }\end{array}$ & $\begin{array}{c}\text { Cobertura } \\
\text { florestal fora } \\
\text { deAPP }\end{array}$ & $\begin{array}{c}\% \text { dos } \\
\text { cob. flor. fora } \\
\text { deAPP }\end{array}$ \\
\hline 1 & 65,85 & 42,24 & 4,62 & 7,0 & 1,87 & 2,74 & 4,2 \\
\hline 2 & 32,29 & 15,99 & 2,56 & 8,0 & 1,34 & 1,22 & 3,8 \\
\hline 3 & 91,09 & 57,67 & 13,20 & 14,5 & 12,62 & 0,58 & 0,6 \\
\hline 4 & 34,95 & 23,73 & 15,35 & 43,9 & 9,69 & 5,65 & 16,2 \\
\hline 5 & 313,27 & 155,41 & 121,80 & 38,9 & 74,20 & 47,60 & 15,2 \\
\hline 6 & 37,39 & 23,91 & 5,98 & 16,0 & 3,86 & 2,11 & 5,7 \\
\hline 7 & 43,09 & 20,14 & 13,61 & 31,6 & 7,79 & 5,81 & 13,5 \\
\hline 8 & 37,28 & 23,32 & 22,68 & 60,8 & 19,04 & 3,63 & 9,8 \\
\hline 9 & 33,07 & 23,16 & 18,68 & 56,5 & 15,22 & 3,44 & 10,4 \\
\hline 10 & 68,17 & 32,76 & 7,22 & 10,6 & 5,40 & 1,82 & 2,7 \\
\hline 11 & 17,92 & 8,84 & 1,59 & 8,9 & 0,98 & 0,60 & 3,4 \\
\hline 12 & 35,02 & 19,61 & 10,93 & 31,2 & 9,07 & 1,86 & 5,3 \\
\hline 13 & 26,56 & 15,72 & 4,58 & 17,2 & 3,47 & 1,10 & 4,1 \\
\hline 14 & 24,66 & 14,51 & 14,02 & 56,9 & 10,73 & 3,29 & 13,3 \\
\hline 15 & 30,26 & 19,93 & 4,49 & 14,9 & 4,24 & 0,24 & 0,8 \\
\hline 16 & 41,99 & 20,28 & 15,65 & 37,3 & 9,80 & 5,84 & 13,9 \\
\hline 17 & 23,06 & 17,73 & 9,73 & 42,2 & 9,56 & 0,16 & 0,7 \\
\hline 18 & 30,32 & 14,42 & 12,15 & 40,1 & 9,53 & 2,61 & 8,6 \\
\hline 19 & 28,47 & 21,39 & 1,96 & 6,9 & 1,65 & 0,30 & 1,1 \\
\hline 20 & 12,63 & 6,36 & 0,81 & 6,4 & 0,67 & 0,13 & 1,1 \\
\hline 21 & 5,27 & 1,63 & 1,15 & 21,8 & 0,34 & 0,80 & 15,3 \\
\hline 22 & 7,93 & 2,89 & 2,74 & 34,6 & 1,87 & 0,87 & 11,0 \\
\hline 23 & 8,27 & 2,76 & 0,08 & 1,1 & 0,08 & 0,00 & 0,0 \\
\hline 24 & 25,41 & 14,02 & 8,70 & 34,2 & 5,55 & 3,14 & 12,4 \\
\hline 25 & 9,49 & 4,29 & 6,47 & 68,1 & 2,80 & 3,66 & 38,6 \\
\hline 26 & 15,66 & 7,45 & 9,14 & 58,4 & 5,18 & 3,96 & 25,3 \\
\hline 27 & 26,59 & 11,57 & 1,14 & 4,3 & 0,90 & 0,23 & 0,9 \\
\hline 28 & 18,48 & 8,92 & 7,04 & 38,1 & 6,17 & 0,86 & 4,7 \\
\hline 29 & 32,63 & 16,71 & 7,12 & 21,8 & 6,03 & 1,09 & 3,4 \\
\hline 30 & 36,88 & 20,45 & 4,76 & 12,9 & 4,76 & 0,00 & 0,0 \\
\hline
\end{tabular}


que em toda a Zona da Mata mineira existe apenas um imóvel com informações cartográficas cadastradas referentes a um único assentamento de sem terras realizado na região. Para os outros imóveis, as informações são somente aquelas prestadas pelos proprietários na Declaração do Imposto Territorial Rural, as quais podem não refletir a realidade, devido à subjetividade das declarações.

A área em estudo está situada nos municípios de Araponga, Canaã e Ervália, que têm o módulo fiscal correspondente a uma área de 28 ha. Por normas, somente para os imóveis cuja área é maior ou igual a 4 módulos fiscais, ( $\geq 112$ ha), os proprietários são obrigados a dar todas as informações constantes na Declaração do Imposto Territorial Rural. Ao analisar a área territorial dos 30 imóveis contidos na área de estudo, verificou-se que apenas um possui mais que 112 ha. Em outras palavras, apenas um proprietário dentro da área de estudo é obrigado a informar corretamente os dados da propriedade para a Declaração do Imposto Territorial Rural (ITR). Os donos dos outros 29 imóveis prestam somente as informações relativas aos dados pessoais, de relacionamento e sobre a estrutura do imóvel, não sendo necessário prestar quaisquer informações referentes à produção e às formas de exploração.

\section{CONCLUSÕES}

Os resultados alcançados na presente pesquisa permitiram concluir que:

A utilização de imagem de alta resolução espacial, como IKONOS II, permite a extração de informações importantes a um cadastro técnico rural, bem como a realização de diagnóstico ambiental e mapeamento da cobertura e uso da terra a partir da classificação visual e visitas a campo.

Verificou-se que 55,01\% das terras na área de estudo seriam inadequadas para uso, por estarem situadas em áreas de preservação permanente, conforme dispõe a resolução número 303 do Conselho Nacional do Meio Ambiente - CONAMA.

Entre os 30 imóveis analisados, apenas dois possuem mais que $20 \%$ das coberturas florestais fora de área de preservação permanente, e 16 têm cobertura florestal em mais que $20 \%$ da área, porém ocupando também área de preservação permanente.

\section{AGRADECIMENTOS}

A Fundação de Amparo à Pesquisa do Estado de Minas Gerais (FAPEMIG), pelo suporte financeiro, e ao Instituto de Geociências Aplicadas de Minas Gerais (IGAMG), pelo apoio técnico e pela permissão de uso de softwares.

\section{REFERÊNCIAS BIBLIOGRÁFICAS}

BRASIL. Lei n. 4.771, de 15 de setembro de 1965 (1982) Secretaria da Agricultura. Instituto Estadual de Florestas. Código Florestal Brasileiro: proteção à fauna, código de pesca, jurisprudência, legislação florestal. Belo Horizonte. p. 9-19.

Gandolfi, S, Leitão Filho, HF, Bezerra, CLF (1995) Levantamento florístico e caráter sucessional das espécies arbustivo-arbóreas de uma floresta semidecídua no município de Guarulhos, SP. Revista Brasileira de Biologia, 55:753-767.

Meira AD (2006) Relatório e Plano de Controle Ambiental Central Geradora Hidrelétrica (CGH) Limoeiro. 82p.

Minas Gerais (2002) Lei Estadual número 14.309; Dispõe sobre a política florestal e de proteção à biodiversidade no Estado. $\mathrm{Pu}$ blicado em Minas Gerais, Diário do Executivo de 20 de junho de 2002.

Nascimento MC, Soares VP, Ribeiro CAAS \& Silva E (2005) Uso do geoprocessamento na identificação de conflito de uso da terra em áreas de preservação permanente na bacia hidrográfica do rio Alegre, Espírito Santo. Ciência Florestal, 15:207-220.

Oliveira FS, Soares, VP, Pezzopane JEM, Gleriani JM, Lima GS, Silva E, Ribeiro CAAS \& Oliveira MAS (2008) Identificação de conflito de uso da terra em áreas de preservação permanente no entorno do Parque Nacional do Caparaó, estado de Minas Gerais. Revista Árvore, 32:899-908.

Ribeiro CAAS, Soares VP, Oliveira MAS \& Gleriani JM (2005) O desafio da delimitação de áreas de preservação permanente. Revista Árvore, 29:203-212.

Segantine, PCL (2005) GPS - sistema de posicionamento global. São Carlos, EESC/Universidade de São Paulo. 381p.

Silva S \& Lock C (1996) Método de pós-classificação de imagens Landsat-TM para o monitoramento de CTR. In: $2^{\circ}$ Congresso Brasileiro de Cadastro Técnico Multifinalitário, Florianópolis, Anais, p. 70-76.

Soares VP, Ribeiro CAAS, Gleriani JM (2007) Utilização de Sistemas de Informações Geográficas no mapeamento de áreas de preservação permanente (APP), para fins de restauração florestal. Revista Ação Ambiental, 36:14-16.

Soares VP, Moreira AA, Ribeiro JC, Ribeiro CAAS \& Silva E (2002) Avaliação das áreas de uso indevido da terra em uma microbacia no município de Viçosa-MG, através de fotografias aéreas e sistema de informação geográfica. Revista Árvore, 26:243-251. 